ISSN: 2162-3104 Print/ ISSN: 2166-3750 Online

Volume 6, Issue 2 (2016), pp. 614-631

(C) Journal of International Students

http://jistudents.org/

\title{
International Student Expectations: Career Opportunities and Employability
}

\author{
Per A Nilsson \\ Umeå University (Sweden) \\ Nannette Ripmeester \\ Expertise in Labour Mobility (The Netherlands)
}

\begin{abstract}
Are mobile students expecting an international experience to have an impact on their career? This was one of the questions in a global survey, with over 150,000 respondents. The survey results showed that the transition from education to the world of work is of increasing importance for students. How to find a job upon graduation is apparently a big concern for current-day students, which dictates their international educational choices to a large extent. Moreover, are there differences between Europe and the rest of the world when it comes to student's expectations of employability? This study found that opportunities for work upon graduation and earning money when studying matter more for non-European students.
\end{abstract}

Keywords: International Student Barometer, StudentPulse, Employability, Studying Abroad, Career Opportunities, Cultural Competence, International Students, Student Expectations

Studying abroad is a unique experience available as an option for present-day students worldwide. According to the OECD (2014), 
approximately 4.5 million students are studying outside their country of citizenship, with an annual growth rate of seven percent. In Europe, about 2.5 million students have participated in the Erasmus program since 1987 (Erasmus, Facts and Figures, 2014); a program financed by the European Union, which facilitates intra-European student mobility.

An international experience can enrich students' academic work and life in general but will the experience improve employability? Some studies indicate that studying abroad can help enhance future career prospects and opportunities. A comprehensive study conducted in Europe concluded that former Erasmus students could not expect higher income and status than their immobile peers but were more often internationally employed (Bracht, Engel, Janson, Over, Schomburg \& Teichler, 2006). From a related study, Norris and Gillespie (2009) concluded that international students' experience of studying abroad had a career impact when it comes to future international work. Furthermore, studies by Wiers-Jenssen (2008; 2013) showed that mobile students more frequently had jobs with international work assignments. Some studies indicate the presence of technical skills upon graduation but the lack of essential soft skills that ensure effective working. Research clearly shows that those soft skills or employability skills are being developed through study or work periods abroad (Jones, 2014; Ripmeester, 2015). Hence, studying abroad will most likely support graduate's employability.

This article deals with the transition from campus to career. The aim is to investigate the employment outcomes of an experience of studying abroad. The study seeks to answer the following research questions:

1) What is the perceived impact of an international study experience on their careers according to mobile students?

2) Have trends and tendencies changed over time when it comes to matching expectations with the labor market after graduation?

3) Are there differences between Europe and the rest of the world when it comes to student's expectations of employability? 


\section{FROM CAMPUS TO CAREER}

\section{Student mobility}

The phenomenon of students going abroad for tertiary studies in this article is defined as student mobility, i.e. any academic mobility which takes place within a student's program of study in postsecondary education (Junor \& Uscher, 2008). The length of absence can range from a semester to the full program of study. There are two main types of student mobility: mobility for an entire program of study (diploma or degree mobility) and for part of a program (credit mobility).

The framework for student mobility seems to be changing constantly. Academic mobility started with an occasional student or teacher going on exchange and gradually developed to mobility within specific programs. According to Knight (2014), the next step will be international education hubs. In the future, more emphasis will be on the different aspects of work-placement. The newly launched Erasmus+ program is now focusing more on entering the labor market and an attempt to diminish the gap between education and career. Similarly, cross-border education was first about cooperation between universities and has now developed into a commercially driven framework. This will probably have an impact on student mobility and work placement in the future. Furthermore, this will likely change the incitements for student mobility and employability when enterprises are working more closely with Higher Education Institutions (HEIs).

\section{A learning experience}

Studying abroad is a great learning experience with many assets, such as linguistic improvement and the cultural experience of living in another country. Thus, it broadens horizons and helps to better understand the world. A study abroad experience supports an increased awareness of and tolerance to other cultures as well as providing training in interacting with individuals of different countries and cultures (Teichler, 2002; King \& Ruiz-Gelices, 2003; Bracht et. al. 2006). The outcomes, when known, are highly appreciated by employers but are often labeled 'personal development' and, therefore often a 'hidden gem' for students with 
international experience (Ripmeester, 2014). The ability for students to transfer tacit knowledge from study-abroad experience to a wellarticulated skill is still underdeveloped and thus not used to its full potential during the application process. However, studying abroad may have the potential to substantially improve employment prospects but the experience needs to be supported to act as bridge from campus to career.

\section{Employability and career}

Some studies on student mobility have focused on employability and career, and the question of whether having studied abroad leads to a greater probability of employment after finishing one's degree. There are indications that graduates who studied abroad during their university studies are more likely to be employed following graduation relative to their non-mobile peers (Di Pietro, 2013). Lianos, Asteriou and Agiomirgianakis (2004) conducted a study of Greeks who graduated from foreign universities subsequently seeking employment in Greece. Note that of the European countries, Greece has the highest number of students studying in another EU member state. According to the study, Greeks who graduate from European universities outside Greece are better placed on the Greek labor market from an employability point of view.

The advantages of studies abroad on labor market chances seems to be present, and one can argue that mobile students seem to have an advantage over those who are non-mobile. As mobile students with an international experience develop intercultural competence, global awareness and foreign language training - exactly the employability skills that are well received on the labor market. The Erasmus Impact Study (Brandenburg, Berghoff \& Taboadela, 2014) suggests that transversal skills are important to employers, skills which are also shown to have improved during an Erasmus period abroad. Thus, one can make the assumption that mobile students have an advantage compared to their immobile peers.

In one recent study (Pollock, 2014), the step from campus to career was examined and how well prepared recent graduates felt for this transition. The survey, conducted on-line under slightly over 200 recent graduates, showed that when leaving the university upon graduation, they are struggling to make the next step in their career. 
Seventy-nine percent of the graduates attested that they needed help in finding employment whereas $46 \%$ felt ill-prepared for the world of work. On top of that, $87 \%$ indicated they were expecting more careers advice from their university to make the transition from campus to career as is shown in figure 1. This underlines that is not only international students who are expecting to be well prepared for the labor market after graduation.

\section{Figure 1. Understanding the transition from campus to career}

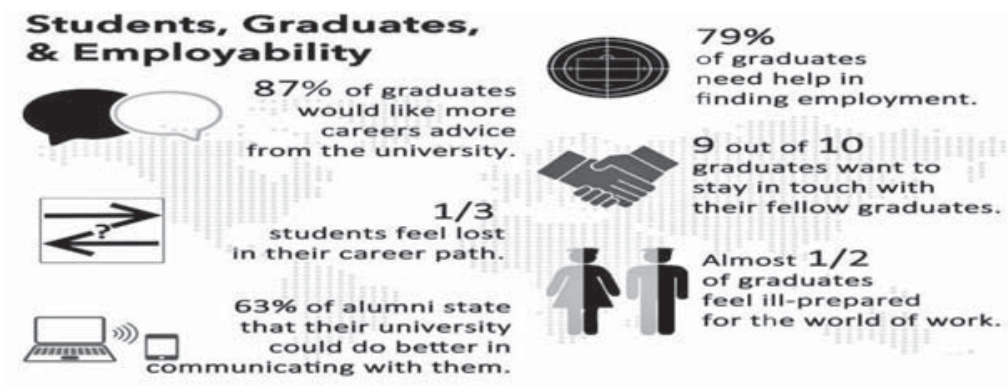

Source: Pollock, A. (2014). Students' employability is a necessity, not a choice. Expertise in Labour Mobility.

However, there is limited evidence about effects of student mobility when it comes to subsequent employment outcomes (Di Pietro, 2013). Prior research has given more attention to general expectations and motivations for students to study abroad (cf. Nilsson, 2013). Nevertheless, it appears students perceive student mobility as a career move (cf. Nilsson, 2015). This study focuses on students' experience when it comes to improving different aspects of their career prospects. They are demanding more options when it comes to internships, professional certificates and real cases built into their education from work life experiences. Moreover, employers' attitudes toward study abroad play a paramount role in motivating students to consider the opportunity of an international experience (Trooboff, de Berg \& Rayman, 2008). A related study from Finland showed that learning from mobility received mixed responses in the labor market. Therefore, a deeper understanding of international competence is required. 
Employers need to recognize competences that are developed through an international experience (Leppanen, Saarinen, Nupponen \& Airas, 2014). Some studies indicate that students with an experience of having lived abroad had more original ideas and creativity compared with a control group of immobile students (Lee, Therriault \& Linderholm, 2012). Thus, students and employers are mostly not aware of hidden skill acquirements in study abroad learning experiences that need to be articulated. Furthermore, Morris-Lange and Brands (2015) showed results from the first international mapping of local support structures for the study-to-work transition of international students in Canada, Germany, the Netherlands and Sweden and indicated that irrespective of a high willingness to stay, many international students fail to find adequate employment.

\section{RESEARCH METHOD}

\section{Participants}

Data for this study was collected through the International Student Barometer (ISB) survey, which monitors students' experiences. Around 200 HEIs and more than 150,000 students participate in the survey every year. The ISB is an annual global benchmarking survey that has been in place for 10 years and in those 10 years surveyed over 2.3 million international students. We used the results of the ISB in the academic year 2014-15 and looked into recent trends based on longitudinal data over a 5-year period. The 2014 ISB received responses from 164,863 students from 209 institutions across 18 countries of which 183 institutions are included in the global benchmark. The survey was directed at international students at the participating HEIs. All international students were asked to fill in the survey during the period November 17th until December 5th, 2014. Non-respondents were mainly the result of students not being motivated to reply and/or having changed their e-mail addresses and therefore it was not possible to reach them. An analysis of the non-participants does not indicate any bias with respect to gender, age or study programs. 
Table 1: Response rate International Student Barometer 2014, $i$ graduate

\begin{tabular}{llll}
\hline & Response & Population & $\begin{array}{l}\text { Response } \\
\text { Rate \% }\end{array}$ \\
\hline Europe (UK excluded) & 21,475 & 65,392 & 33 \\
Global & 164,863 & 599,453 & 28 \\
& & & \\
\hline
\end{tabular}

\section{Questionnaire}

A web-based survey was distributed to all registered international students with a semi-standardized online format adapted and customized for each partner institution. Thus, the analyses are based on survey data monitoring the students' level of expectations after a period studying abroad. The web survey used a questionnaire covering arrival, learning, living, support, recommendation, application, and choice of institution. Institution-specific results compared against comparator groups, national and international benchmarks.

The International Graduate Insight Group (i-graduate) is an independent benchmarking and research service, delivering comparative insights for the education sector worldwide. For the analysis an independent samples t-test was used, i.e. to statistically test the significance of mean differences. Further, t-tests were also used to compare mean scores of individual institutions against the overall Student Barometer mean. All statistical analyses were performed by i-graduate.

The limitations with the ISB are based on the fact that HEIs have to choose to take part in this study run by i-graduate, however the survey was chosen because of its availability and unique data set. Nonetheless, the limitation of the dataset will of course make conclusions drawn from the study tentative.

\section{StudentPulse}

To further strengthen the findings, results of the StudentPulse survey were added. The StudentPulse 2014 surveyed 2,366 prospective students. This is an annual survey i-graduate undertakes to understand the decision-making process of prospective 
international students; why they want to study abroad, what drives their choices and how they make their study decisions. Combining both datasets helped us understand how both prospective and current international students make certain study decisions and as well as the main drivers behind those decisions. Also, for the StudentPulse survey, our main focus has been on the topic of this article: student satisfaction in general and with a focus on employment outcomes in particular, again disregarding the richness of the dataset on other topics.

\section{Employment Outcomes}

The literature review shows the implied suggestion that study abroad periods enhance a graduate's employability when they transfer from the university to the labor market. However, the literature also shows the need for more detailed information on what drives student choices and how does this relate to employment outcomes of a study abroad period. In the following section of this chapter, we examine emerging trends in student satisfaction mainly based on i-graduate's ISB.

\section{Impact on students' international experience on their careers}

To understand student satisfaction with their institution, we have looked at the data to see what has most impact on recommendation from current international students. The element within the learning area of the ISB survey that has most impact on a high recommendation score for an institution - hence the issue that apparently is considered of most importance to international students turns out to be employability. In the ISB of the academic year 201415, this element scored 33\%. The graph below shows an overview of the top 5 most important elements in the learning section for derived importance, i.e. how important the particular element is for international students to rate their HEI favorably on. Over a period of 5 years, employability, i.e. learning that will help me to get a good job, is a key element for student satisfaction as table 2 clearly shows.

The ISB data show the importance of employability to current international students and i-graduate's StudentPulse survey looks at prospective international students. 
Table 2: An overview of the top 5 most important elements when it comes to Learning Satisfaction over time. Learning Satisfaction (Derived Importance - over time)

\begin{tabular}{llllll}
\hline Global ISB & 2010 & 2011 & 2012 & 2013 & 2014 \\
\hline Employability & $33 \%$ & $36 \%$ & $34 \%$ & $34 \%$ & $33 \%$ \\
Course organization & - & $34 \%$ & $33 \%$ & $33 \%$ & $33 \%$ \\
Course content & $33 \%$ & $34 \%$ & $34 \%$ & $34 \%$ & $32 \%$ \\
Teaching ability & $33 \%$ & $33 \%$ & $33 \%$ & $33 \%$ & $31 \%$ \\
Expertise of lectures & $30 \%$ & $31 \%$ & $31 \%$ & $30 \%$ & $30 \%$ \\
\hline
\end{tabular}

Source: International Student Barometer, 2010-15, i-graduate

The job upon graduation is echoed strongly amongst this group. When asked about reasons for opting for an international study, falling just under broadening my experience and quality of education is the aspect improving my career prospects, noticeably high at $95 \%$. The most important reason for a study abroad experience is thus expanding one's horizon. However career prospects are extremely important in the decision-making. This importance of labor market prospects is reiterated by the survey outcomes when choosing an institution. After the fairly predictable top results of quality of teaching, learning facilities, and quality of research, the next most important aspect for prospective students is opportunities for work placement or practical experience. Ninety-two percent of respondents in the survey stated that this aspect was either important or very important when deciding for a certain HEI.

For $69 \%$ of the respondents, improving career prospects is their main driver for an international study. Interestingly, when looking at the results by intended level of study, the students aiming for a research postgraduate study find improving career prospects on average 5\% more important than students intending to study at any other level. Those aiming to undertake postgraduate research level study are also more likely to have a family that wants them to study in another country.

The data from the ISB 2014-15 show that some institutions do better than others with regards to preparing their international students for the next step after graduation; however, for all participating 209 
HEIs in the survey, we observed a drop in the learning area satisfaction when their students where asked about employability (learning that would help me get a good job) and the opportunities for work experience/work placements as a part of my studies or the careers advice coming from academic staff (advice and guidance on long-term job opportunities and careers from academic staff).

Figure 2. Important factors for prospective students in their decision-making process before studying abroad.

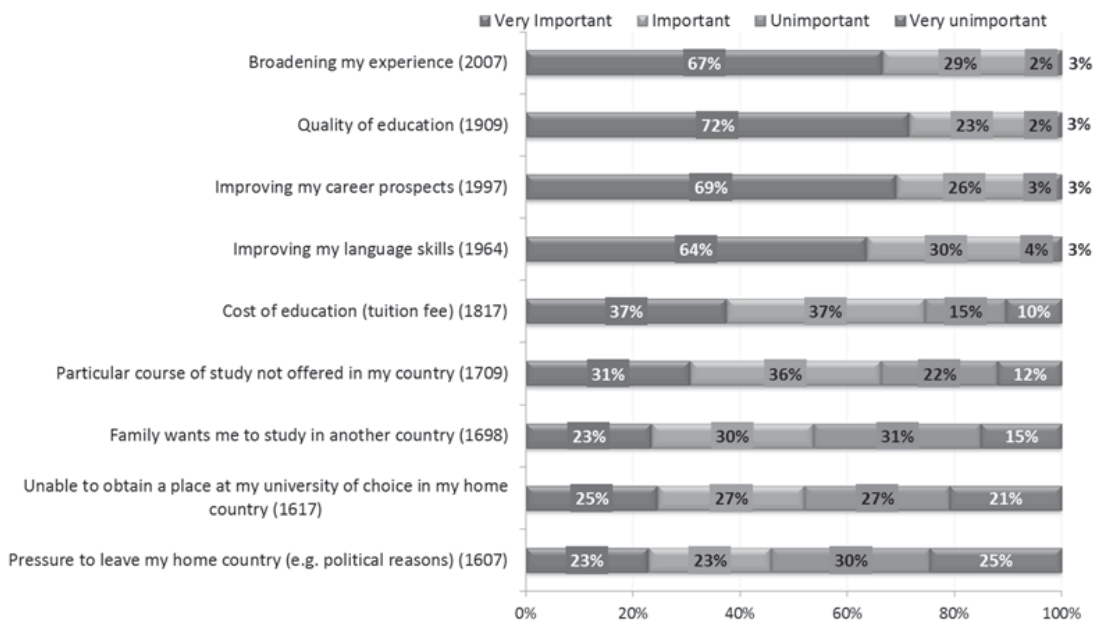

Source: StudentPulse, 2014, i-graduate

This signals to an area that has been slightly disregarded by many HEIs as one of their responsibilities. The current day student has clearly a different idea here and expects action from their institution to support them in making the transition from education to the labor market.

\section{Differences between Europe and the rest of the world}

We have scrutinized the data of current international students and whether there is a difference between international students that opt for a student experience in continental Europe compared to those that decide to study elsewhere in the world. Opportunities for work upon graduation and earning potential of the chosen degree matter respectively $8 \%$ and $4 \%$ more in the study decision of international 
students that decide for a study experience outside of continental Europe. Whether these students are more career conscious than their peers who opt for a study in continental Europe is difficult to say based on the data.

Table 3: Important factors for studying abroad. A comparison between students from continental European with the rest of the world.

\begin{tabular}{lccc} 
Items & $\begin{array}{c}\text { Global ISB } \\
\mathrm{n}=164,863\end{array}$ & $\begin{array}{c}\text { Europe ISB } \\
\mathrm{n}=21,475\end{array}$ & Difference \\
\hline Social life & $78 \%$ & $78 \%$ & $0 \%$ \\
Specific course title & $91 \%$ & $91 \%$ & $0 \%$ \\
Institutions reputation & $93 \%$ & $92 \%$ & $1 \%$ \\
Cost of study & $85 \%$ & $87 \%$ & $2 \%$ \\
Personal safety & $89 \%$ & $86 \%$ & $3 \%$ \\
Location & $80 \%$ & $77 \%$ & $3 \%$ \\
Cost of living & $86 \%$ & $83 \%$ & $3 \%$ \\
Research quality & $90 \%$ & $86 \%$ & $4 \%$ \\
Earning potential & $89 \%$ & $85 \%$ & $4 \%$ \\
Permanent residence & $57 \%$ & $50 \%$ & $7 \%$ \\
University Scholarship/Bursary & $73 \%$ & $66 \%$ & $7 \%$ \\
Proximity to my home country & $37 \%$ & $30 \%$ & $7 \%$ \\
Work opportunities & $73 \%$ & $65 \%$ & $8 \%$ \\
Opportunities to further studies & $76 \%$ & $67 \%$ & $9 \%$ \\
Opportunities to work while & & & \\
studying & $68 \%$ & $58 \%$ & $10 \%$ \\
Visa process & $66 \%$ & $52 \%$ & $14 \%$ \\
Teacher reputation & $79 \%$ & $62 \%$ & $17 \%$ \\
\hline
\end{tabular}

Source: International Student Barometer, 2014, i-graduate

The largest variations between both groups are in the reputation of the teacher and the visa process as is displayed in table 3. For students that opt for an international student experience outside continental Europe, the reputation of an individual academic supervisor or professor is $17 \%$ more important in their study decision than for those international students that opt for a study experience in continental Europe. The ease of getting a visa to study in the country matters more to those who decide to study outside of continental Europe than for those that decide to study in continental Europe, which leads to the 
assumption that international students within Europe may often have an EU nationality making the importance of a study visa less essential for them.

Figure 3. What would make graduates stay or leave their host country?

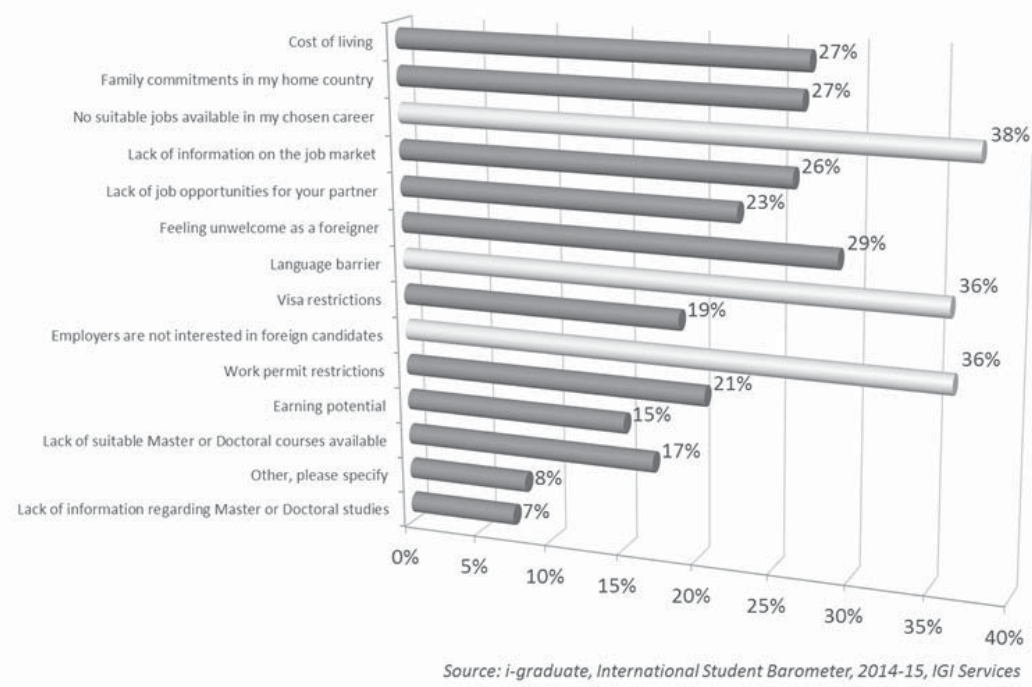

Source: International Student Barometer, 2014, i-graduate

In continental Europe, we have added an extra question in the ISB 2014-15, trying to understand what would make graduates stay in or leave their host country. We have asked international students studying at the participating European ISB partner institutions what would make them leave their host country upon graduation. The data provide an indication of the anticipated issues that international students expect upon graduation in continental Europe. Again, the job market and access to that job market (including the ability to speak the local language) were more dominantly present than other factors as is shown in figure 3. The respondents emphasized future career prospects and opportunities before 'personal' items and items related to policies, rules and regulations. Most striking is the top 1 reason for international students in continental Europe to leave their study destination upon graduation: $38 \%$ expected that there would be no suitable jobs for them in their chosen career followed by $36 \%$ 
expecting a language barrier upon graduation and $36 \%$ believing employers are not interested in foreign candidates. Based on the data, one cannot make a conclusion that $38 \%$ will leave their study country, but it does send a signal that international students feel not adequately prepared and expect some serious hurdles to make the next step on the job market of their study destination.

When looking at the differences between full degree students and exchange students, we can see that the opportunities for work upon graduation is the biggest difference. This matters $11 \%$ more for degree seeking students in their decision-making process.

\section{DISCUSSION}

The transition from education to the world of work is increasing in importance, not just when we look at what current and prospective student's perspectives influence on their choices, but also if we look at the programs of higher education conferences across the globe. The number of sessions dealing with employability has substantially increased in the last two years.

As ISB and StudentPulse research shows, being employable is a driver for both current and prospective international students. Being able to make the transition to the world of work upon graduation is exactly what drives both prospective and current students in their choice for a study abroad experience at a certain HEI. Thus, how to find a job upon graduation is apparently a big concern for current day students. Not getting this right as an institution upon graduation for the current generation of students might have an impact upon the intake of future students. Hence, strengthening career services at educational levels is important. Student mobility is about learning from other cultures and business methods. It dictates their educational choices to a large extent, as proven by the eminent role that employability plays in choosing and recommending an institution by prospective and current international students respectively. It is up to the HEI to think of solutions that support the next step after graduation. The time that HEIs could say their role ended upon graduation of their students is over as current day (international) students expect support in making the transition from obtaining their degree to (their first steps on) the labor market. Thus, it's important to 
improve data and analysis of graduate labor market outcomes to further enhance provision with a labor market orientation. For universities, it remains a challenge to bridge the gap between campus and career - many Higher Education experts see student mobility as a way of creating better career prospects for graduates. Study abroad is helpful as Ripmeester (2015) also shows, however, it is not the panacea for the issue at large. One way of easing the bridging is introducing more professional experiences into the curriculum, be it via mock-up (virtual) situations or real internships and thus working closer with industries, enterprises and other organizations.

Besides internships and studies abroad, intercultural competence can be developed through engaging students in discussions and serious gaming that provide exposure to different cultures, not just to cultural differences in general, but also to specific situations with an emphasis on soft skills in the world of work. However, for institutions it is equally important that academic staff has a good understanding of working life and understand the link between the academic learning and the use of that learning in a professional environment. Students are, for instance, asking for possibilities to take courses aimed at professional certifications. It is interesting to notice that many international students are aspiring for Ph.D. positions. For instance at Swedish universities approximately 40 percent of newly enrolled Ph.D. Students' are internationally recruited (The Official Statistics of Sweden, 2013), showing that graduate studies (such as receiving a Ph.D. in Sweden) are bridging the gap between education and working life.

However, the most obvious conclusion is that the job-upongraduation-challenge is a mutual concern for both students and universities. HEIs need to start thinking beyond the obvious career advisory services and deliver support in the language of modern students: easy to grasp, visual, available 24/7, digital. In the meantime, careers advice has globalized too: current day students want to understand what skills employers are looking for in particular countries and sectors, and how to ensure they understand the cultural differences that play a role in job hunting. If students understand why a North American resume does not include a date of birth and why someone's age matters in a CV aimed at a European employer, we are helping students make the transition in life that probably has most 
impact in how they view their study experience and eventually what turns them into "Brand Ambassadors" for their HEI.

In bridging the gap for our students, we should not disregard the role employers can play. Several of the studies referred to in this chapter show that employers are an important piece in this puzzle. Furthermore, Ripmeester (2014) shows that employers strongly believe that the HEIs are in the driver's seat when it comes to the design and delivery of the curricula. For institutions the challenge now is to come up with solutions that make a connection with employers and prepare their students for the global job market.

This study shows that international students are expecting studying abroad to have an impact on their career and employability, this is especially true for the degree students who are studying a full program. Furthermore, the ISB survey shows that non-European students are expecting more opportunities for work after graduation than peers from continental Europe. The matching of the expectations with employment outcomes is still far apart and needs to be bridged. This is now done by some countries when easing their immigration policies to encourage the temporary or permanent immigration of international students (OECD, 2008). Thus, it's essential to coordinate labor market and education policies and to include labor market perspectives and actors in policy development.

\section{REFERENCES}

Bracht, O., Engel, C., Janson, K., Over, A., Schomburg, H., \& Teichler, U. (2006). The Professional Value of ERASMUS Mobility. Final report of the VALERA project. International Centre for Higher Education Research (INCHER-Kassel), University of Kassel, Kassel, Germany

Brandenburg, U., Berghoff, S., \& Taboadela, O. (2014). The Erasmus impact study - effects of mobility on the skills and employability of students and the internationalisation of higher education institutions. Luxembourg: European Union. Retrieved, from: http://ec.europa.eu/education/library/study/2014/erasmusimpact_en.pdf 
Di Pietro, G. (2013). Do study abroad programs enhance the employability of graduates? Discussion papers series IZA DP No. 7675. Forschungsinstitut zur Zukunft der Arbeit Institute for the Study of Labor. Bonn, Germany.

European Commission. (2014). Erasmus, facts and figures. The European Union support for student and staff exchange and university cooperation in 2012-2013. Luxembourg. Publication Office of the European Union. Retrieved from: http://ec.europa.eu/education/library/statistics/ay-12-13/factsfigures_en.pdf

Junor, S., \& Usher, A. (2008). Student mobility \& credit transfer. A national and global survey. Educational Policy Institute. Retrieved from: http://www.educationalpolicy.org/ publications/pubpdf/credit.pdf

Jones, E. J. (2014). Graduate employability and internationalization of the curriculum at home. International Higher Education, 78 68. Retrieved from: http://ejournals.bc.edu/ojs/index.php/ ihe/article/view/5799/5169

King, R., \& Ruiz-Gelices, E. (2003). International student migration and the European 'Year Abroad': effects on European identity and subsequent migration behaviour. International Journal of Population Geography, 9(3), 229-252.

Knight, J. (2012). Student mobility and internationalization: trends and tribulations. Research in Comparative and International Education, 7(1), 20-33.

Knight, J. (2014). Three generations of crossborder higher education: New developments, issues and challenges. In B. Streitwieser (Eds), Internationalisation of higher education and global mobility, (pp. 43-58). Oxford, UK: Oxford Studies in Comparative Education.

Lee, C. S., Therriault, D. J., \& Linderholm, T. (2012). On the cognitive benefits of cultural experience: Exploring the relationship between studying abroad and creative thinking. Applied Cognitive Psychology, 26(5), 768-778. doi: 10.1002/acp.2857. 
Leppanen, J., Saarinen, M., Nupponen, M., \& Airas, M. (2014). Hidden competences: Facts and figures. Helsinki, Finland: CIMO.

Lianos, T. P., Asteriou, D., \& Agiomirgianakis, G.M. (2004). Foreign university graduates in the Greek labour market: employment, salaries and over education. International Journal of Finance and Economics, 9(2), 151-164.

Morris-Lange, S., \& Brands, F. (2015). Train and retain: Career support for international students in Canada, Germany, the Netherlands and Sweden, SVR's Research Unit: Study 20152. Berlin, Germany.

Nilsson, P. A. (2013). Expectations and experiences of temporarily studying abroad. História. Revista da FLUP, 3(4), 183-198.

Nilsson, P. A. (2015). Expectations and experiences of inbound students: Perspectives from Sweden. Journal of International Students, 5 (2), 161-174.

Norris, E. M., \& Gillespie, J. (2009). How study abroad shapes global careers: evidence from the United States. Journal of Studies in International Education, 13(3), 382-397.

Organisation for Economic Co-operation and Development, OECD. (2014). Education at a Glance 2014: OECD Indicators. OECD Publishing, Paris. Retrieved from: http://www.oecd.org/edu/Education-at-a-Glance-2014.pdf

Organisation for Economic Co-operation and Development, OECD. (2008). Tertiary Education for the Knowledge Society, 1(2), Paris, France: OECD Publishing.

Pollock, A. (2014), Student employability is a necessity, not a choice. Expertise in Labour Mobility. Retrieved from http://www.labourmobility.com/student-employabilitynecessity-choice/

Ripmeester, N. (2014). International businesses: Consumers of global talent? In Verlag, J. V. (ed.), Handbook of internationalisation, (21-32). Berlin, Germany: Dr. Josef Raabe Verlag.

Ripmeester, N. (2015). The value of global experience. Expertise in labour mobility. Retrieved from: http://www.labourmobility.com/the-value-of-globalexperience/ 
The Official Statistics of Sweden, SCB. (2013). Utländska doktorander. Temarapport. Retrieved from: http://www.scb.se/Statistik/_Publikationer/UF0544_2013T01_ BR_A40BR1304.pdf

Teichler, U. (2002). Erasmus in the Socrates programme. Findings of an evaluation study. Bonn, Lemmens.

Trooboff, S., Vande Berg, M., \& Rayman, J. (2008). Employer attitudes toward study abroad. Interdisciplinary Journal of Study Abroad, 15, 19-33.

Wiers-Jenssen, J. (2008). Does higher education attained abroad lead to international jobs? Journal of Studies in International Education, 12(2), 101-130.

Wiers-Jenssen, J. (2013). Degree mobility from the Nordic countries: Background and employability. Journal of Studies in International Education, 17(4), 471-491. doi: $10.1177 / 1028315312463824$.

PER A. NILSSON, MA, has a long experience working with internationalization at Swedish universities. $\mathrm{He}$ has been the international director at Umeå University for more than ten years and is now writing a thesis about student mobility. He was awarded a Rotary Foundation Scholarship and received a Master of Arts in 1983 from University of Minnesota, USA. Email: per.a.nilsson@umu.se

NANNETTE RIPMEESTER is Director Client Services Europe for i-graduate - a leading benchmarking organization responsible for the International Student Barometer (ISB). She is director of Expertise in Labour Mobility, and involved in the educational gaming app CareerProfessor.works bridging education to the world of work. She works with graduate employers across the globe. Email: n.ripmeester@labourmobility.com

Manuscript submitted: July 6, 2015 Manuscript Revised: November 23, 2015 Accepted for publication: December 11, 2015 